\title{
Utilization of meiofauna as a food source by a grassbed fish, the spotted dragonet Callionymus pauciradiatus
}

\author{
Susan M. Sogard* \\ Rosenstiel School of Marine and Atmospheric Science, University of Miami, 4600 Rickenbacker Causeway, \\ Miami, Florida 33149, USA
}

\begin{abstract}
The feeding ecology of the spotted dragonet Callionymus pauciradiatus was examined over a 15 mo period. This small epibenthic fish inhabits seagrass beds of southern Florida and the Caribbean. The fish fed almost exclusively on meiofauna, with harpacticoid copepods comprising an average of $89 \%$ of the diet. Analysis of selectivity of prey items, based on comparison of the diet composition with natural meiofauna abundances, showed that the dragonets preferentially consume harpacticoids, mites, and ostracods. Results of gastric evacuation experiments to determine the rate of food passage through the gut gave an estimated daily ration of 1000 copepods fish $^{-1}$.
\end{abstract}

\section{INTRODUCTION}

The spotted dragonet Callionymus pauciradiatus Gill is a small epibenthic fish patchily distributed in seagrass beds of southern Florida and the Caribbean. Its ecology has not been previously examined. This study was undertaken in an attempt to assess the role of this species in the trophic dynamics of grassbeds. While predation on the invertebrate macrofauna of seagrass beds has been studied extensively (e.g. Kikuchi, 1966; Brook, 1975; Adams, 1976; Nelson, 1979; Stoner, 1979; Livingston, 1982), little is known about the utilization of grassbed meiofauna. Preliminary examination of gut contents of $C$. pauciradiatus indicated that this fish consumed large amounts of meiofauna.

There is some controvery over the role of meiofauna in the energy transfer of benthic ecosystems. A large portion of these organisms are generally assumed to be detritivores (Coull, 1973). Several studies have concluded that there is minimal predation pressure on the meiofauna and that most of their production is returned to the detrital pool (McIntyre, 1969; Marshall, 1970) or

\footnotetext{
- Present address: National Audubon Society Research Laboratory, 115 Indian Mound Trail, Tavernier, Florida 33070, USA
}

consumed by other meiofauna (McIntyre and Murison, 1973; Heip and Smol, 1975). As a group, the meiofauna would thus form the top of a short food chain.

In contrast, meiofauna, especially the harpacticoid copepods, are the primary food for several juvenile fishes in a variety of habitats (e.g. Bregnballe, 1961; Kaczynski et al., 1973; Grossman et al., 1980; Godin, 1981; Alheit and Scheibel, 1982). In tropical grassbeds, the emerald clingfish Acyrtops beryllinus and the darter goby Gobionellus boleosoma depend on meiofauna for food through all life stages (Gould, 1965; Carle and Hastings, 1983).

The typically abundant meiofauna, then, are either a large potential source of transfer of detrital energy or, if the terminus of a short food chain, a significant barrier to energy flow. Investigation of the utilization of meiofauna is thus important in understanding the overall trophic dynamics of the ecosystem in question. In the trophic web of a seagrass bed these organisms may represent a significant, underestimated component.

\section{MATERLALS AND METHODS}

Spotted dragonets were collected from 1 of 3 grassbed sites in Biscayne Bay, Miami, Florida. Collections were made with an $80 \mathrm{~cm}$ wide push net 2 or 3 times a month from September, 1980 through November, 1981. 
The majority of collections were taken within $2 \mathrm{~h}$ of low tide and at depths of less than $1.5 \mathrm{~m}$. Time of sampling varied throughout daylight hours and included three night collections. Fish were immediately preserved in $10 \%$ formalin upon capture. After 1 to $2 \mathrm{wk}$ they were transferred to $40 \%$ isopropanol.

Methods used in assessing the feeding ecology of Callionymus pauciradiatus included quantification of the diet, comparison of diet composition to available food, and determination of the rate of gastric evacuation. At least 3 fish from each sampling date, and a total of 113 fish, were selected for diet analysis. The fish were dissected and the entire gut removed and divided into fore, mid, and hindgut sections. Divisions were made at the pylorus and a characteristic curve in the posterior part of the intestine. An additional 22 fish were examined on the basis of total gut contents, with the gut not divided into sections. Gut contents were teased apart and identified to major taxon. Lengths of up to 15 prey items of each type were measured in each section of the gut.

The total gut contents of 69 fish were weighed to calculate the percentage of body weight present in fish collected at different times of day. The ash-free dry weights (AFDW) of the gut contents and the fish with its emptied gut were measured to the nearest $\mu \mathrm{g}$ on a microbalance. Percentage of body weight ingested by the fish was calculated as (AFDW of gut contents/ AFDW of fish) $\times 100$. Fish were grouped into 1 of 6 time periods according to the time of collection and an analysis of variance used to compare diel differences.

Estimations of natural meiofauna abundances were based on cores taken in March, June, September, and December of 1981. For each sampling, 3 to 4 cores of $4.7 \mathrm{~cm}$ diameter were taken from a dense area of Halodule wrightii at one of the collection sites. This site typically had high abundances of spotted dragonets; it was assumed that the fish were feeding in the same area where captured. In the laboratory, the top $1.5 \mathrm{~cm}$ of each core was sliced off and washed through a $102 \mu \mathrm{m}$ sieve. While a sieve of this size allows many meiofaunal organisms to pass through, it was used in this study to examine the meiofauna likely available to the fish as food.

Decanting and sieving, as recommended by Hulings and Gray (1971), were utilized to partially separate organisms from sediment. Material retained on the sieve was examined under a dissecting microscope and the number of organisms in each major meiofaunal group counted. Blades of Halodule wrightii included in the cores were thoroughly examined for the presence of phytal meiofauna. It was not known if the fish were feeding on epibenthic or phytal organisms. The cores represent the total pool of meiofauna available in the size range known to be consumed by the fish. In this study, all organisms less than $3.0 \mathrm{~mm}$ and greater than $0.1 \mathrm{~mm}$ in length were considered available prey.

Movement was often the only means of detecting an organism among the detritus and sediment. Therefore, all cores were examined within $2 \mathrm{~d}$ following collection, allowing enumeration while the organisms were still alive. Cores examined at the end of this period showed no consistent change in numbers of meiofauna compared with cores examined immediately after removal.

After enumeration, all core samples were preserved in $10 \%$ buffered formalin. They were later washed and stained with a solution of Sudan Black B in $70 \%$ ethanol. This lipid-specific stain was used to distinguish Foraminifera which were alive at the time of collection, since live and dead forams could not be readily differentiated in the fresh samples. Results of all cores from each sampling date were averaged and the mean abundances of the meiofaunal groups in an area of $10 \mathrm{~cm}^{2}$ determined. 'Soft-bodied' meiofaunal taxa (Hulings and Gray, 1971) were excluded from the analysis as they would probably not be recognizable in the fish gut even if they were ingested. This problem was considered minor in this study as little unidentifiable matter was found in the fish guts.

The selectivity index derived by Chesson (1978) was used to compare the proportions of meiofaunal groups in the diet with those occurring in the grassbed. Only those taxa and size ranges that occurred at least once in the fish guts were included in the analysis. Other items were unavailable either by active choice or passive limitations. The index is derived as follows:

$$
\alpha_{i}=r_{1} n_{i}^{-1}\left(\sum_{l}^{m} r_{i} n_{i}^{-1}\right)^{-1}
$$

where $\alpha_{1}=$ index of preference of prey type $i_{i} r_{1}=$ percentage of item $i$ in diet; $n_{i}=$ percentage of item $\mathrm{i}$ in available food $\mathrm{m}=$ total prey types. A critical value of $\alpha_{i}=1 / \mathrm{m}$ is used to determine selectivity. If $\alpha_{i}$ is greater than $1 / m$ the predator shows a positive selection for the item. If $\alpha_{1}$ is less than $1 / m$, there is selection against an item, and if $\alpha_{1}=1 / m$, the predator is taking that item in proportion to its natural abundance. Selectivity indices were derived for three size groups of Callionymus pauciradiatus and for the combined total

The rate at which food was evacuated from the gut was calculated by a variation of Elliott's (1972) method, which involves feeding a known biomass of food to starved fish and weighing the material remaining in the gut after discrete periods of time. The resultant exponential relation is of the following form:

$$
Y_{t}=Y_{0} \cdot e^{-R t}
$$

where $Y_{t}=$ dried digestible organic matter in gut; $Y_{0}=$ dried digestible organic matter in meal $R=$ gastric evacuation coefficient; $t=$ time in $h$. In the 
present study, numbers of organisms remaining in the gut were used instead of biomasses, since weight measurement of the small quantity of gut contents was imprecise. If the number of organisms remaining in the gut also decreases exponentially with time, then this equation remains valid.

Dragonets in the laboratory were maintained on a diet of Artemia nauplii prior to gut evacuation experiments. For each experiment 6 fish were transferred to a $10 \mathrm{l}$ aquarium containing 500 to 600 harpacticoids collected from the field or laboratory cultures. Fish were allowed to feed for $45 \mathrm{~min}$ and were observed to ensure that all fish were eating. They were then removed to either filtered sea water with no food or to the Artemia supply. Fish were killed $0,4,6,8,10$, or $12 \mathrm{~h}$ after the end of the test feeding period and the position of any harpacticoids in the gut noted. This method allowed comparison of fish held with a continuous food supply and those held with no food. Stepien (1976) demonstrated with stained prey that a larval sea bream, Archosargus rhomboidalis with a continuously full gut, evacuated its food more rapidly than one removed from its food source. The gastric evacuation coefficient, $R$, was calculated using Elliott's (1972) equation and the number of copepods (initial and final) present in the guts.

The gastric evacuation coefficient $(R)$ can be used to calculate the biomass consumed over a particular time interval by (Elliott and Persson, 1978):

$$
C_{t}=\frac{\left(S_{t}-S_{o} \cdot e^{-R t}\right) R t}{1-e^{-R t}}
$$

where $\mathrm{C}_{\mathrm{t}}=$ amount consumed $\mathrm{t}=$ time in $\mathrm{h}_{;} \mathrm{S}_{\mathrm{o}}=$ initial amount of food in meal; $S_{t}=$ amount of food remaining in gut after $t h_{i} R=$ gastric evacuation coefficient. A basic assumption is that the fish feed continuously during period $\mathrm{C}_{\mathrm{t}}$. Observations of spotted dragonets held in aquaria and the fact that fishes sampled throughout daylight hours always contained food in all 3 sections of the gut indicate that this assumption was met. All feeding experiments were conducted at $25^{\circ} \mathrm{C}$. Information generated from these experiments was used to determine the daily ration of harpacticoid copepods for an individual fish.

\section{RESULTS}

\section{Gut contents}

None of the dissected fish had an empty gut. Examination of the formalin in which fish were placed upon capture showed no evidence of regurgitation. There was little possibility that the fish consumed additional prey after capture in the net, because most food items could readily pass through the $6.4 \mathrm{~mm}$ mesh. The items contained within the gut, then, were considered an accurate representation of the diet.

The major food of Callionymus pauciradiatus was meiofauna in the size range of 0.2 to $1.0 \mathrm{~mm}$. Within this group, harpacticoid copepods were by far the most important food, with ostracods, mites, nematodes, gastropods, and amphipods contributing minor fractions. Observations of fish in aquaria showed that prey were plucked individually using a method of feeding very similar to 'pipetting' as described for cyprinids by Gosline (1973).

The frequency of occurrence of each prey type, i.e. the percentage of fish which contained a particular food item, is listed in Table 1, along with the mean

Table 1. Frequency of occurrence and mean numerical percentage of food items found in guts of spotted dragonets $(\mathrm{n}=135)$

\begin{tabular}{|c|c|c|}
\hline Prey type & $\begin{array}{c}\text { Frequency } \\
\text { of occur- } \\
\text { rence }\end{array}$ & $\begin{array}{l}\text { Numeri- } \\
\text { cal per- } \\
\text { centage }\end{array}$ \\
\hline Harpacticoid copepods & 100 & 89 \\
\hline Ostracods & 76 & 3 \\
\hline Mites & 57 & 2 \\
\hline Nematodes & 50 & 2 \\
\hline Gastropods & 41 & 1 \\
\hline Foraminifera & 37 & $<1$ \\
\hline Gammarid amphipods & 31 & $<1$ \\
\hline Detritus and seagrass & 24 & $<1$ \\
\hline Unidentifiable (non-crustacean) & 24 & $<1$ \\
\hline Tanaids & 22 & $<1$ \\
\hline Unidentifiable crustaceans & 20 & $<1$ \\
\hline Barnacle cypris larvae & 16 & $<1$ \\
\hline Copepod nauplii & 15 & $<1$ \\
\hline Bivalves & 15 & $<1$ \\
\hline Invertebrate eggs (non-copepod) & 12 & $<1$ \\
\hline Cumaceans & 6 & $<1$ \\
\hline Polychaetes & 5 & $<1$ \\
\hline Isopods & 3 & $<1$ \\
\hline Caridean shrimp & 2 & $<1$ \\
\hline Cyclopoid copepods & 2 & $<1$ \\
\hline Calanoid copepods & 1 & $<1$ \\
\hline Caprellid amphipods & 1 & $<1$ \\
\hline Brachyuran megalops & 1 & $<1$ \\
\hline
\end{tabular}

numerical percentage of the total gut contents comprised by each prey type. Both parameters were strikingly similar across all months of the study (Sogard, 1982). Therefore, only the overall values are presented here. On a numerical basis, harpacticoids averaged $89 \%$ of an individual fish's diet. While a high percentage of the fish examined contained ostracods and mites in the gut, these items were much fewer in number than the copepods.

Comparison of the relative percentage of food in each of the 3 sections of the gut with the time of 


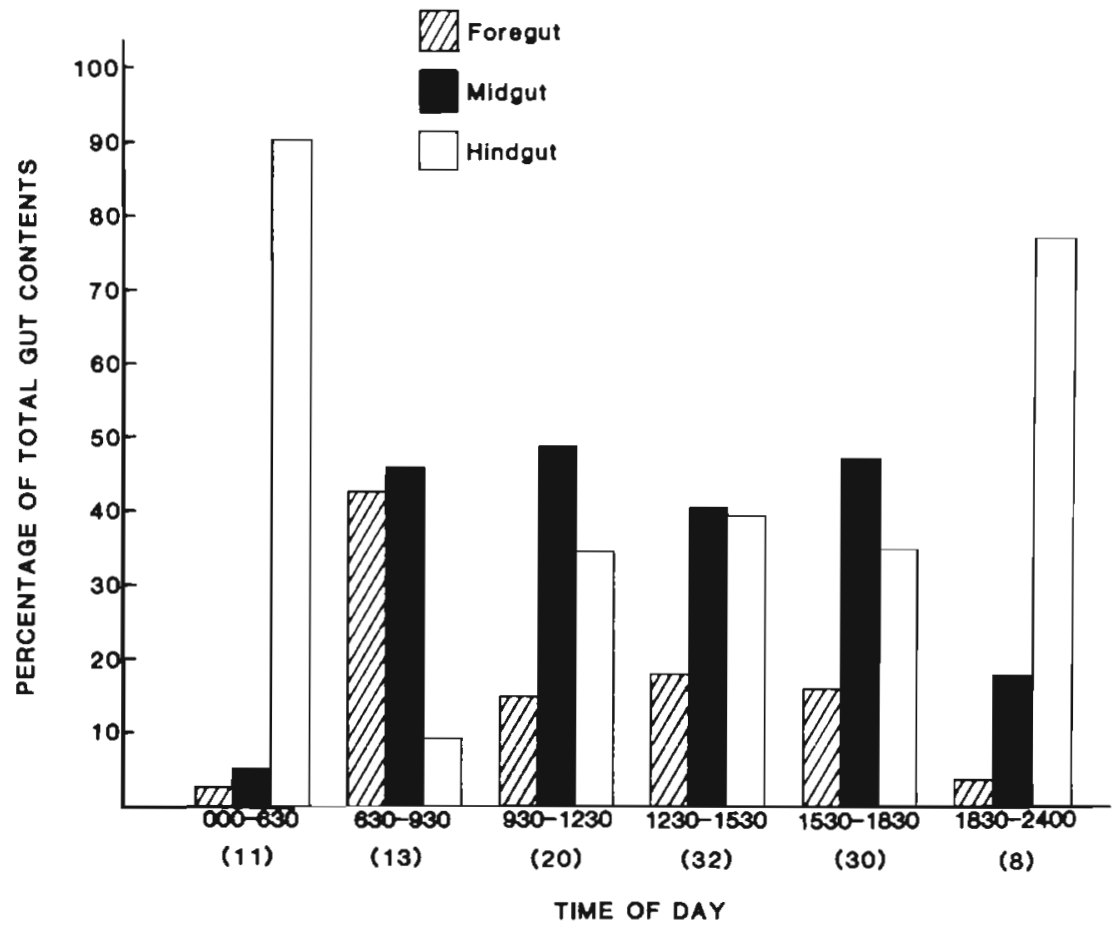

Fig. 1. Mean percentage of total gut contents in each section of the gut. Numbers in parentheses: number of fish collected in each time period

capture indicated that the spotted dragonets are diurnal foragers (Fig. 1). While fish caught at night often had a large number of food items in the gut, these were usually concentrated in the hindgut, and were generally packed into a greatly distended rectum. Fish observed in aquaria at night were still and often partially buried in the substrate. Fish collected in early morning hours had little food in the hindgut and the greatest percentage of food in the foregut, indicating that they had started to feed. The gut contents of fish collected during daylight hours were typically distributed throughout the gut, indicating continuous feeding once daily activity has begun.

The mean percentage of ash-free body weight comprised by gut contents ranged from 0.66 to $2.23 \%$ (Fig. 2). An analysis of variance showed a significant difference in gut weight percentage by time of day $(\mathrm{F}=4.62, \mathrm{p}<.01)$. While there was an increase in relative gut content weight during predawn hours compared to the previous time span, this was partly

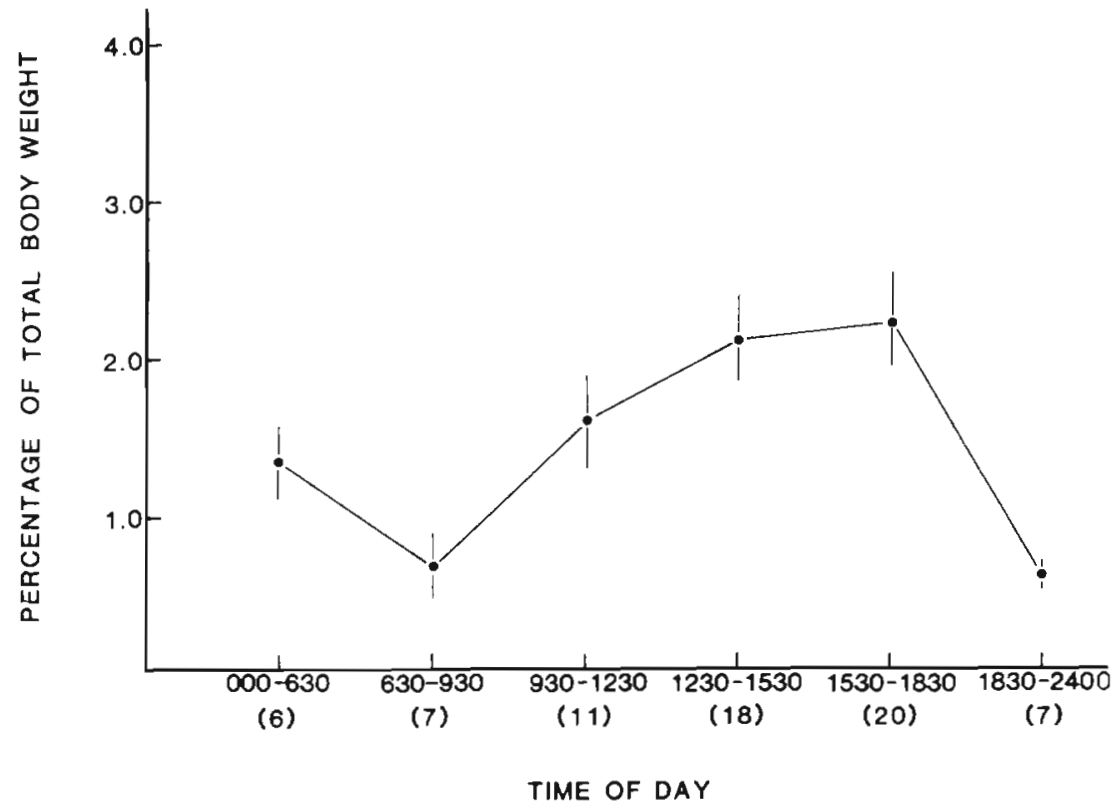

Fig. 2. Mean percentage ( \pm S.E.) of body weight comprised by gut contents. Data from all months and sizes of fish combined. Numbers in parentheses: number of fish collected in each time period 
due to a single fish which had, in fact, fed throughout the night and had a full gut. Other fish in this time period contained a large amount of food, but it was well compacted in the hindgut. The large drop in gut weight percentage in early morning reflected the defecation of gut material upon initiation of daytime activity. The relative amount of food present in each section of the gut was a better indicator of feeding periodicity than either the total items in the gut or the gut content weight.

The total number of food items in the gut was, as expected, correlated with standard length of fish ( $\mathrm{r}=$ .45. $\mathrm{p}<.001$ ). For daytime samples, the total ranged from 3 to 935 items (Fig. 3). There was no monthly

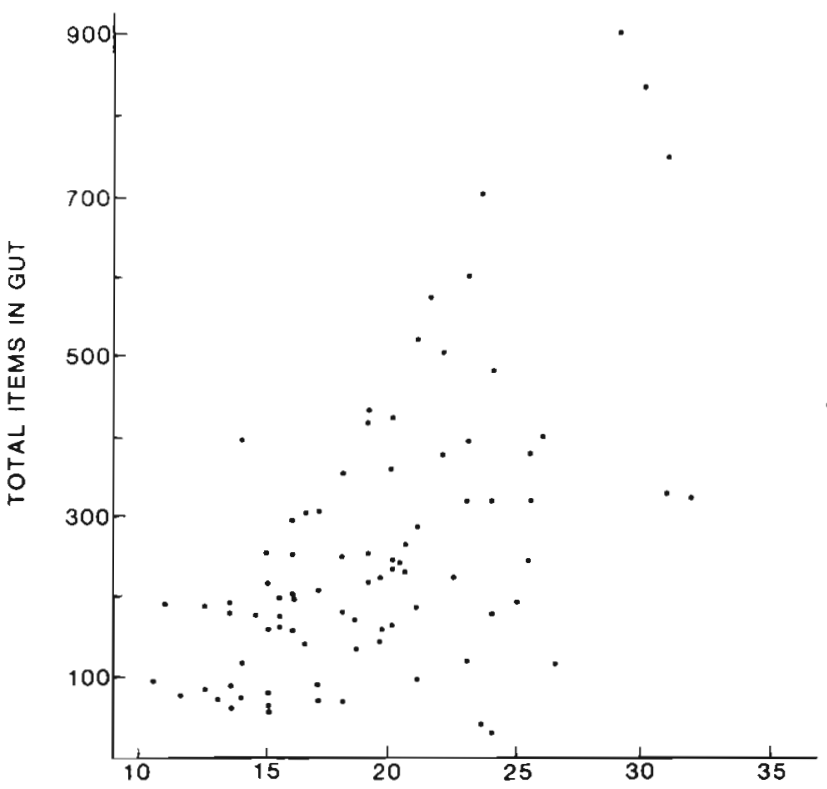

STANDARD LENGTH IN MM

Fig. 3. Relation of standard length to total items in the gut for all spotted dragonets collected between 1000 and $1800 \mathrm{~h}$

$$
(\mathrm{n}=84)
$$

difference which could not be explained by the size distribution of the fish. Sex of the fish had no effect on the total items consumed.

Larger sized fish ate larger copepods ( $r=.56$, $\mathrm{p}<.001$ ), although there was a wide variation in the mean size of copepods eaten (Fig. 4). Mouth width was significantly related to standard length (Sogard, 1982), and likely affected the mean size of copepods eaten. Large fish did not exclude small copepods from the diet.

\section{Meiofauna}

The abundance of meiofaunal groups varied widely among replicate core samples. The relative composition of the groups, however, remained fairly constant.

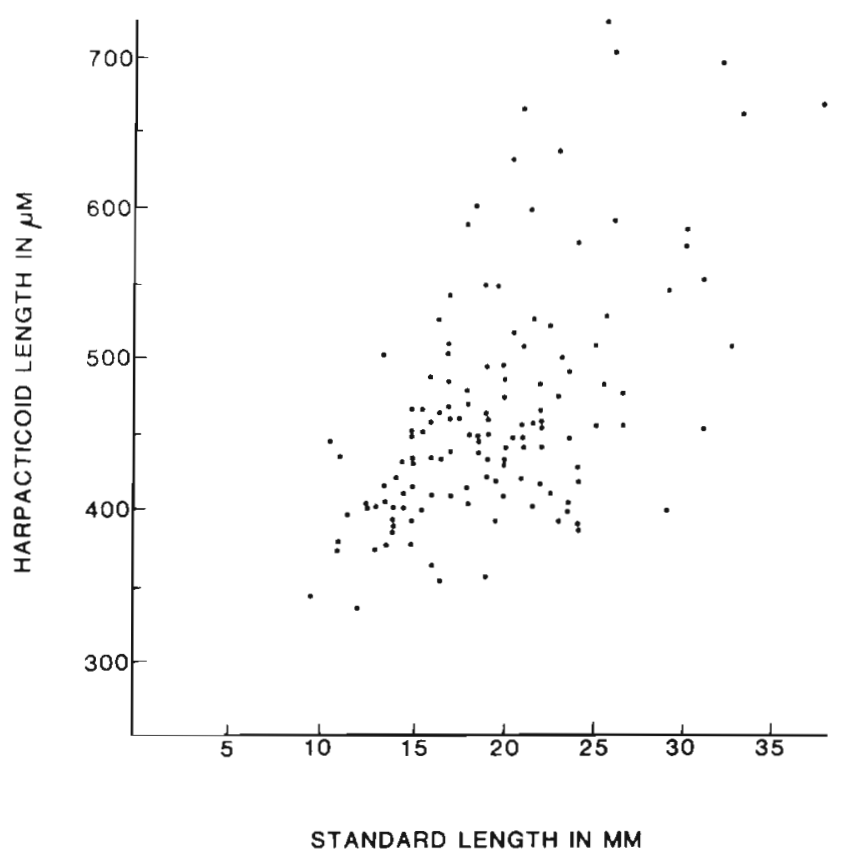

Fig. 4. Relation of standard length of spotted dragonets to mean length of ingested harpacticoids $(n=135)$

The mean abundance of each group, expressed as number per $10 \mathrm{~cm}^{2}$, is presented for each sampling period in Table 2. Nematoda and Foraminifera alternated as the most abundant group. Harpacticoids were generally third in abundance except in December, when they outnumbered the nematodes. After these 3 groups, abundances of remaining taxa were generally low. The small sample size of this study, combined with the typically high patchiness of meiofauna, limits the validity of seasonal comparisons. Therefore, selectivity indices were based on the overall mean abundances of meiofauna listed in Table 2.

\section{Selectivity}

Prey selectivity values derived for each of 3 standard length size classes are presented in Table 3 . For this study, there were 15 prey types, and therefore, $1 / m$ (the value indicating no selection) $=0.067$. The calculated selectivity indices were arbitrarily categorized in the following manner: values of 0.057 to $0.077=$ no selection, 0.027 to $0.057=$ negative selection, values below $0.027=$ strong negative selection, 0.077 to $0.107=$ positive selection, and values above $0.107=$ strong positive selection.

Harpacticoids, ostracods, and mites were positively selected by all sizes of fish. With larger crustaceans, there were differences in selectivity according to size of fish. Amphipods were preferred prey for larger fish, were taken in proportion to their abundance by 
Table 2. Abundance of meiofaunal organisms per $10 \mathrm{~cm}^{2}$ in a Halodule bed of Biscayne Bay. March values are average of 3 cores; other months are average of 4 cores

\begin{tabular}{|c|c|c|c|c|c|c|c|c|c|c|}
\hline \multirow[t]{2}{*}{ Taxa } & \multicolumn{2}{|c|}{ March } & \multicolumn{2}{|c|}{ June } & \multicolumn{2}{|c|}{ September } & \multicolumn{2}{|c|}{ December } & \multicolumn{2}{|c|}{ Yearly average } \\
\hline & $\overline{\mathrm{x}}$ & S. E. & $\bar{x}$ & S.E. & $\overline{\mathrm{x}}$ & S.E. & $\bar{x}$ & S.E. & $\overline{\mathrm{x}}$ & S. E. \\
\hline Nematodes & 345.8 & $(117.3)$ & 63.4 & $(17.6)$ & 164.3 & $(17.3)$ & 58.2 & $(8.4)$ & 157.9 & $(67.2)$ \\
\hline Foraminifera & 154.5 & $(64.3)$ & 174.7 & (63.1) & 138.9 & $(37.3)$ & 85.3 & $(30.2)$ & 138.3 & (19.1) \\
\hline Harpacticoids & 92.8 & (39.9) & 53.0 & (22.5) & 50.7 & $(14.9)$ & 89.9 & $(14.2)$ & 71.6 & (11.4) \\
\hline Polychaetes & 10.9 & $(2.8)$ & 13.8 & $(3.4)$ & 23.1 & $(8.1)$ & 5.2 & (1.9) & 13.3 & $(3.7)$ \\
\hline Copepod nauplii & 13.3 & (3.3) & 9.8 & $(3,8)$ & 21.3 & (6.4) & 2.6 & (1.2) & 11.7 & (3.9) \\
\hline Gastropods & 2.3 & (1.8) & 2.9 & (1.6) & 12.7 & (5.1) & 6.6 & $(5.0)$ & 6.1 & $(2.4)$ \\
\hline Ostracods & 5.2 & (2.1) & 3.5 & $(1.6)$ & 1.7 & (1.3) & 3.2 & $(1.2)$ & 3.4 & $(0.7)$ \\
\hline Bivalves & 0.4 & $(0.4)$ & 1.7 & $(0.8)$ & 5.2 & $(3.0)$ & 1.7 & (1.3) & 2.3 & $(1.0)$ \\
\hline Mites & 3.2 & (3.2) & 0.6 & $(0.6)$ & 2.9 & $(2.2)$ & 0.3 & $(0.3)$ & 1.8 & $(0.8)$ \\
\hline Amphipods & 2.3 & (2.3) & 1.1 & $(0.7)$ & 0.1 & $(0.1)$ & 2.9 & (1.8) & 1.6 & (0.6) \\
\hline Tanaids & 0 & (0) & 0.9 & $(0.2)$ & 0.6 & $(0.4)$ & 2.0 & (1.2) & 0.9 & $(0.4)$ \\
\hline Isopods & 0.2 & $(0.2)$ & 0.1 & $(0.1)$ & 0.3 & $(0.3)$ & 0 & (0) & 0.2 & $(0.1)$ \\
\hline Shrimp & 0 & (0) & 0 & (0) & 0.6 & $(0.6)$ & 0 & (0) & 0.2 & $(0.2)$ \\
\hline Calanoids & 0 & (0) & 0.3 & $(0.2)$ & 0.3 & $(0.2)$ & 0.1 & $(0.1)$ & 0.2 & (0.1) \\
\hline Cumaceans & 0.6 & $(0.3)$ & 0 & (0) & 0 & (0) & 0 & (0) & 0.2 & $(0.2)$ \\
\hline
\end{tabular}

Table 3. Callionymus pauciradiatus. Selectivity indices and level of selection for prey ingested. ++ strong positive selection, + positive selection, 0 no selection, - negative selection, - - strong negative selection

\begin{tabular}{|c|c|c|c|c|c|c|c|c|}
\hline \multirow{3}{*}{ Prey item } & \multicolumn{8}{|c|}{ Standard length } \\
\hline & \multicolumn{2}{|c|}{$\begin{array}{l}\text { All fish } \\
(n=135)\end{array}$} & \multicolumn{2}{|c|}{$\begin{array}{c}9.0-16.0 \mathrm{~mm} \\
(\mathrm{n}=43)\end{array}$} & \multicolumn{2}{|c|}{$\begin{array}{c}16.5-21.0 \mathrm{~mm} \\
(\mathrm{n}=49)\end{array}$} & \multicolumn{2}{|c|}{$\begin{array}{c}21.5-38.0 \mathrm{~mm} \\
(\mathrm{n}=43)\end{array}$} \\
\hline & $\alpha_{i}$ & Selection & $\alpha_{i}$ & Selection & $\alpha_{i}$ & Selection & $\alpha_{1}$ & Selection \\
\hline Harpacticoids & .284 & $+t$ & .350 & ++ & .306 & ++ & .228 & ++ \\
\hline Mites & .187 & ++ & .240 & $+t$ & .201 & ++ & .145 & ++ \\
\hline Ostracods & .185 & ++ & .143 & ++ & .215 & ++ & .182 & $+t$ \\
\hline Amphipods & .068 & 0 & .031 & - & .072 & 0 & .085 & + \\
\hline Shrimp & .061 & 0 & .000 & -- & .014 & -- & .137 & ++ \\
\hline Tanaids & .059 & 0 & .093 & + & .057 & 0 & .041 & - \\
\hline Cumaceans & .052 & - & .000 & -- & .090 & + & .047 & - \\
\hline Gastropods & .035 & - & .040 & - & .020 & -- & .045 & - \\
\hline Isopods & .035 & - & .020 & -- & .000 & -- & .066 & 0 \\
\hline Bivalves & .012 & -- & .023 & $-\ldots$ & .006 & -- & .012 & -- \\
\hline Nauplii & .009 & -- & .036 & - & .002 & -- & .001 & -- \\
\hline Calanoids & .009 & -- & .011 & -- & .019 & -- & .007 & $\ldots$ \\
\hline Nematodes & .003 & -- & .007 & -- & .003 & -- & .001 & -- \\
\hline Forams & .002 & -- & .002 & -- & .001 & -- & .002 & -- \\
\hline Polychaetes & .001 & -- & .002 & -- & .002 & -- & .001 & -- \\
\hline
\end{tabular}

\section{Gastric evacuation}

medium-sized fish, and were rejected by small fish. Tanaids had the reverse pattern. Medium-size fish positively selected cumaceans, which were ignored by larger and smaller fish. Shrimp were selected by larger fish and not eaten by medium and small fish. While it must be emphasized that, in comparison to harpacticoids, none of these prey items was of substantial importance to the fish (Table 1), the differences according to size suggest slight changes in feeding with development.
Results of the gastric evacuation experiments are listed in Table 4. There was no apparent difference in the rate of gastric evacuation between fish held with food (Artemia) and those held in filtered sea water after feeding on copepods. Therefore, results from the 2 groups were combined. The data indicated an exponential decrease in the number of copepods remaining in the gut with time $\left(r^{2}=0.96\right)$, allowing use of Elliott's (1972) equation. On a numerical basis, the gastric evacuation coefficient was 0.22 . Using this number in 
Table 4. Number of harpacticoid copepods remaining in the guts of spotted dragonets 0 to $12 \mathrm{~h}$ after test meal

\begin{tabular}{|crrr|}
\hline $\begin{array}{c}\text { Hours } \\
\text { after } \\
\text { feeding }\end{array}$ & $\overline{\mathrm{x}}$ & S.E. & $\mathrm{n}$ \\
\hline 0 & 18.0 & 6.2 & 6 \\
4 & 4.0 & 2.0 & 2 \\
6 & 3.6 & 1.9 & 8 \\
8 & 2.1 & 2.0 & 8 \\
10 & 1.2 & 0.8 & 6 \\
12 & 0 & 0 & 2 \\
\hline
\end{tabular}

conjunction with the mean number of copepods present in the gut at each hour of the day (Table 5), and summing according to the methods of Elliott and Persson (1978), a daily ration of approximately 1000 copepods fish $^{-1}$ was estimated.

Table 5. Number of harpacticoids present in the guts of spotted dragonets collected at each hour of the day. Data from all months and sizes of fish combined

\begin{tabular}{|rrr|}
\hline Time & $\overline{\mathrm{x}}$ & $\mathrm{n}$ \\
\hline 630 & 119 & 11 \\
730 & 93 & 3 \\
830 & 140 & 6 \\
930 & 177 & 6 \\
1030 & 233 & 6 \\
1130 & 296 & 10 \\
1230 & 188 & 6 \\
1330 & 201 & 18 \\
1430 & 90 & 9 \\
1530 & 287 & 17 \\
1630 & 182 & 3 \\
1730 & 299 & 17 \\
1830 & 110 & 6 \\
1930 & 104 & 3 \\
2030 & 188 & 5 \\
2130 & 34 & 3 \\
\hline
\end{tabular}

\section{DISCUSSION}

There is a clear dependence of Callionymus pauciradiatus on meiofauna for food. This species can therefore be added to the growing list of established meiofauna consumers (e.g. Bregnballe, 1961; Sibert et al., 1977; Godin, 1981; Alheit and Scheibel, 1982), providing a well based contrast to conclusions that meiofauna are the top of a short food chain (McIntyre, 1969; Heip and Smol, 1975). In spotted dragonet-populated grassbeds, the meiofauna serve an important role in the transfer of detrital and microfloral energy to the macrofauna. Although accounts of predation on $C$. pauciradiatus are not known, this species is likely consumed by predaceous grassbed fishes and possibly decapod crustaceans and wading birds.

Coull and Bell (1979) suggested that the importance of meiofauna as a food source for upper trophic levels is related to the grain size of the sediment in which they live. Studies which have found significant consumption of meiofauna have concentrated on muddy or detrital sediments, while those concluding that meiofauna are not transferred to upper trophic levels have concentrated on sandy habitats. With the much deeper redox discontinuity layer in sands, meiofauna have more opportunity to burrow and escape from predation (Coull and Bell, 1979). Grassbeds, with their high detrital load, would clearly fall into the first category. The redox layer is near the sediment surface and, in very thick grassbeds, even the water just above the substrate may at times become anoxic (Heck and Orth, 1980). These conditions may restrict the meiofauna to the sediment-water interface and the grassblades themselves, where they become more readily accessible to predators.

To examine the effect of predation by spotted dragonets on the harpacticoid community, it is necessary to know the species composition and reproductive capacity of the copepods. Unfortunately, values of fecundity, generation time, and yearly production have not been examined in tropical grassbed harpacticoids.

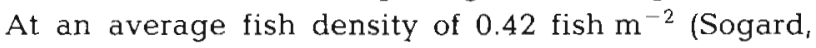
1982), an average harpacticoid density of 71,600 copepods $\mathrm{m}^{-2}$ (Table 2), and a daily ration of 1000 copepods $\mathrm{fish}^{-1}$, the fish would remove an estimated $0.59 \%$ of the harpacticoid standing crop each day. Densities of spotted dragonets ranged from 0.05 to 1.75 fish $\mathrm{m}^{-2}$ (Sogard, 1982) and harpacticoid densities from 50,700 to $92,800 \mathrm{~m}^{-2}$ (Table 2). At the extremes of these values, the fish would be removing daily $0.05 \%$ to $3.45 \%$ of the standing crop. Even if the dragonets consume as much as $10 \%$ of the annual harpacticoid production, the relatively rapid turnover rate of the copepods makes food limitation for the dragonets unlikely.

Bregnballe (1961) found that juvenile plaice consumed $1.2 \%$ of the standing crop of harpacticoids per day, but concluded that the fish were too few in number to cause any major decrease in copepod abundance. Alheit and Scheibel (1982) estimated a maximum daily predation rate of $0.1 \%$ of the standing crop and concluded that predation by juvenile tomtates Haemulon aurolineatum would have little effect on harpacticoid populations. In this study as well it seems that, while predation on harpacticoids by spotted dragonets is substantial, the fish exert little regulatory control on overall copepod abundances.

There was no apparent difference in evacuation rate between fish held without food after the test meal and 
those allowed to continue feeding. However, the presence of large amounts of food in the hindgut of fish caught just before dawn indicated that evacuation is slowed at night, when the fish are still and metabolism is probably lowered. Laurence (1971) found that evacuation time in larval Micropterus salmoides was substantially longer during darkness than during daylight hours, when the fish are more active. A difference in evacuation rate according to time of day would affect calculation of daily rations.

Differences in selectivity of prey according to the size of the fish indicate slight ontogenetic shifts in diet composition. However, these are minor, and the food source of the dragonet remains virtually the same throughout its life in the grassbed.

Its small mouth and highly protrusible jaws allow Callionymus pauciradiatus to select individual prey organisms, unlike detritivores which indiscriminately forage on benthic material, ingesting some meiofauna in the process. Many juvenile fishes in the grassbed consume copepods (Carr and Adams, 1973; Alheit and Scheibel, 1982; Livingston, 1982), but most display a complete ontogenetic shift in diet with growth. None of the fish species so far examined in grassbeds of southern Florida has shown as strong a dependence on harpacticoids as that of the spotted dragonet. Lengthfrequency analysis indicates that this species has a short life span of 1 yr or less (Sogard, 1982). Its small size as an adult is a further adaptation enabling it to readily exploit the resource of grassbed meiofauna.

The harpacticoid-dragonet food chain represents a potentially significant mode of transfer of detrital energy to the water column. In this system, the fish are totally dependent on meiofaunal production for their energetic requirements.

Acknowledgements. I would like to thank Drs. M. R. Roman and S.S. Bell for valuable comments and criticism of the manuscript. Dr. Roman, Dr. C. R. Robins, and Dr. M. R. Reeve provided equipment and advice throughout the course of this study. Dr. S. Siddall and M. Gottfried provided valuable assistance with computer analysis.

\section{LITERATURE CITED}

Adams, S. M. (1976). Feeding ecology of eelgrass fish communities. Trans. Am. Fish. Soc. 105: 514-519

Alheit, J., Scheibel, W. (1982). Benthic harpacticoids as a food source for fish. Mar. Biol. 70: 141-147

Bregnballe, F. (1961). Plaice and flounders as consumers of the microscopic bottom fauna. Meddr Danm. Fisk.-og. Havunders 3: 133-182

Brook, I. (1975). Some aspects of the trophic relationships among higher consumers in a seagrass community. Ph. D. thesis, University of Miami, Coral Gables, Florida

Carle, K. J., Hastings, P. A. (1983). Selection of meiofaunal prey by the darter goby, Gobionellus boleosoma (Gobiidae). Estuaries 5: 316-318

Carr, W. E. S., Adams, C. A. (1973), Food habits of juvenile marine fishes occupying seagrass beds in the estuarine zone near Crystal River, Florida. Trans. Am. Fish. Soc. 102: $511-540$

Chesson, J. (1978). Measuring preference in selective predation. Ecology 59: 211-215

Coull, B. C. (1973). Estuarine meiofauna: a review: trophic relationships and microbial interactions. In: Stevenson, L. H. Colwell, R. R. (ed.) Estuarine microbial ecology. University of South Carolina Press, Columbia, S. C., p. $499-511$

Coull, B. C., Bell, S. S. (1979). Perspectives of marine meiofaunal ecology. In: Livingston, R. J. (ed.) Ecological processes in coastal and marine systems. Plenum Publishing, New York, p. 189-216

Elliott, J. M. (1972). Rates of gastric evacuation in brown trout, Salmo trutta L. Freshwat. Biol 2: 1-18

Elliott, J. M., Persson, L. (1978). The estimation of daily rates of food consumption for fish. J. Anim. Ecol. 47: 977--991

Godin, J.-G. J. (1981). Daily patterns of feeding behavior, daily rations, and diets of juvenile pink salmon (Oncorhynchus gorbuscha) in two marine bays of British Columbia. Can. J. Fish. aquat. Sci. 38: 10-14

Gosline, W. A. (1973). Considerations regarding the phylogeny of cypriniform fishes, with special reference to structures associated with feeding. Copeia (1973): 761-776

Gould, W. R. (1965). The biology and morphology of Acyrtops berrylinus, the emerald clingfish. Bull. mar. Sci. 15: $165-188$

Grossman, G. D., Coffin, R., Moyle, P. B. (1980). Feeding ecology of the bay goby (Pisces: Gobiidae). Effects of behavioral, ontogenetic, and temporal variation on diet. J. exp. mar. Biol. Ecol. 44: 47-59

Heck, K. L., Orth, R. J. (1980). Seagrass habitats: the roles of habitat complexity, competition and predation in structuring associated fish and motile macrobenthic assemblages. In: Kennedy, V. S. (ed.) Estuarine perspectives. Academic Press, New York, p. 419-464

Heip, C., Smol, N. (1975). On the importance of Protohydra leuckarti as a predator of meiobenthic populations. In: Persoone, G., Jaspers, E. (ed.) 10th European Marine Biology Symposium. Ostend, Belgium, Vol. 2. Universa Press, Wetteren, p. 285-296

Hulings, N. C., Gray, J. S. (1971). A manual for the study of meiofauna. Smith. Contr. Zool. 78: 1-83

Kaczynski, V. W., Feller, R. J., Clayton, J., Gerke, R. J. (1973). Trophic analysis of juvenile pink and chum salmon (Oncorhynchus gorbuscha and O. keta) in Puget Sound. J. Fish. Res. Bd Can. 30: 1003-1008

Kikuchi, $T$ (1966). An ecological study on animal communities of the Zostera belt in Tomioka Bay, Amakusa, Kyushu. Publ. Amakusa Mar. Biol. Lab. 1: 1-106

Laurence, G. C. (1971). Digestion rate of larval largemouth bass. N. Y. Fish Game J. 18: 52-56

Livingston, R. J. (1982). Trophic organization of fishes in a coastal seagrass system. Mar. Ecol. Prog. Ser. 7: 1-12

Marshall, N. (1970). Food transfer through the lower trophic levels of the benthic environment. In: Steele, J. H. (ed.) Marine food chains. University of California Press, Berkeley, p. 52-66

McIntyre, A. D. (1969). Ecology of marine meiobenthos. Biol. Rev. 44: 245-290

McIntyre, A. D., Murison, D. J. (1973). The meiofauna of a flatfish nursery ground. J. mar. biol. Ass. U. K. 53: 93-118 
Nelson, W. G. (1979). Experimental studies of selective predation on amphipods: consequences for amphipod distribution and abundance. J. exp. mar. Biol. Ecol. 38: 225-245

Sibert, J., Brown, T. J., Healey, M. C., Kask, B. A., Naiman, R. J. (1977). Detritus-based food webs: exploitation by juvenile chum salmon (Oncorhynchus keta). Science, N.Y. 196: 649-650

Sogard, S. M. (1982). Feeding ecology, population structure, and community relationships of a grassbed fish, Calliony- mus pauciradiatus, in southern Florida. M. S. thesis, University of Miami, Coral Gables, Florida

Stepien, W. P., Jr. (1976). Feeding of laboratory-reared larvae of the sea bream Archosargus rhomboidalis (Sparidae). Mar. Biol. 38: 1-16

Stoner, A. W. (1979). Species-specific predation on amphipod crustacea by pinfish (Lagodon rhomboides): mediation by macrophyte standing crop. Mar. Biol. 55: 201-207

This paper was presented by Professor K. R. Tenore; it was accepted for printing on February 2, 1984 